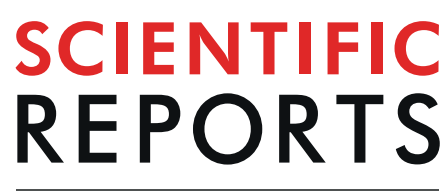

natureresearch

\title{
OPEN Sex-specific up-regulation of IncRNAs in peripheral blood of patients with schizophrenia
}

Received: 20 June 2019

Accepted: 22 August 2019

Published online: 04 September 2019

\section{Hamid Fallah ${ }^{1}$, Iman Azari ${ }^{1}$, Seyedeh Morvarid Neishabouri' ${ }^{2}$, Vahid Kholghi Oskooei ${ }^{3,4}$, Mohammad Taheri ${ }^{5}$ \& Soudeh Ghafouri-Fard ${ }^{1}$}

Schizophrenia as a common disabling psychiatric disorder has been associated with dysregulation of several genes and pathways among them are those being regulated by long non-coding RNAs (IncRNAs). Based on the acknowledged roles of IncRNAs in neurodevelopment, in the current study, we assessed expression of six IncRNAs namely HOXA-AS2, Linc-ROR, MALAT1, MEG3, SPRY4-IT1 and UCA1 in peripheral blood of 60 patients with schizophrenia and 60 healthy subjects. HOXA-AS2, Linc-ROR, MEG3, SPRY4-IT1 and UCA1 levels were significantly higher in total patients compared with total controls. However, when evaluating expression of genes in sex-based subgroups, the differences in the expression of these IncRNAs were significant only among females. Assessment of partial correlation between expression of IncRNAs and age of study participants after controlling the effect of sex, revealed significant correlations for HOXA-AS2, MALAT1 and UCA1 in both patients and controls. Besides, expressions of Linc-ROR and SPRY4-IT1 were correlated with age only in patients. Significant pairwise correlations were recognized between expression levels of IncRNAs in both patients with schizophrenia and controls. Based on the area under curve (AUC) values, SPRY4-IT1 had the best performance in differentiation of female patients with schizophrenia from female controls (AUC $=0.85$, $\mathrm{P}<0.0001$ ). Combination of Linc-ROR, MEG3, SPRY4-IT1 and UCA1 expression levels could differentiate female patients with $95.2 \%$ sensitivity, $76.9 \%$ specificity and diagnostic power of $0.88(P<0.0001)$. The current study suggests the presence of a sex-based dysregulation of IncRNAs in patients with schizophrenia and their possible application as diagnostic biomarkers.

Schizophrenia is a devastating psychiatric disorder which affects approximately $1 \%$ of individuals throughout their lifespan. This disorder is characterized by the existence of an arrangement of symptoms including positive symptoms (hallucinations, delusions, abnormal concentrating and movement disorder), negative symptoms (apathy, lack of pleasure, avolition, and flattening), and cognitive symptoms (defects in administrative function and attention $)^{1}$. Although the main cause of schizophrenia has not been recognized yet, there is a bulk evidences indicating the role of gene expression dysregulation in the pathogenesis of this disorder ${ }^{2-4}$. Long non-coding RNAs (lncRNAs) are the major regulators of gene expression which execute this role via binding to histone-modifying proteins, transcription factors and RNA polymerase $\mathrm{II}^{5}$. Numerous expression profiling studies have demonstrated aberrant expression of lncRNAs in the peripheral blood and the brain tissues of patients with schizophrenia $^{6,7}$. However, the role of some other lncRNAs in the pathogenesis of this psychiatric disorder has not been explored. In the current study, we have used a literature-based method to identify lncRNAs with putative but indirect or unappreciated roles in schizophrenia. We selected six lncRNAs namely HOXA-AS2, Linc-ROR, MEG3, SPRY4-IT1, UCA1 and MALAT1 to assess their expression in peripheral blood of patients with schizophrenia and healthy subjects. Any of the lncRNAs selected for this investigation affects one plausible aspect of schizophrenia pathogenesis. HOXA transcript antisense RNA 2 (HOXA-AS2) is transcribed from HOXA cluster between and

${ }^{1}$ Department of Medical Genetics, Shahid Beheshti University of Medical Sciences, Tehran, Iran. ${ }^{2}$ Department of Psychiatry, Shahid Beheshti University of Medical Sciences, Tehran, Iran. ${ }^{3}$ Department of Laboratory Sciences, School of Paramedical Sciences, Torbat Heydariyeh University of Medical Sciences, Torbat Heydariyeh, Iran. ${ }^{4}$ Neuroscience Research Center, Torbat Heydariyeh University of Medical Sciences, Torbat Heydariyeh, Iran. ${ }^{5}$ Urogenital Stem Cell Research Center, Shahid Beheshti University of Medical Sciences, Tehran, Iran. Hamid Fallah and Iman Azari contributed equally. Correspondence and requests for materials should be addressed to M.T. (email: mohammad_823@yahoo.com)orS.G.-F. (email:s.ghafourifard@sbmu.ac.ir) 


\begin{tabular}{|c|c|c|c|}
\hline Primer Name & Sequence & $\begin{array}{l}\text { Primer } \\
\text { Length }\end{array}$ & $\begin{array}{l}\text { PCR Product } \\
\text { Length }\end{array}$ \\
\hline MEG3-F & TGGCATAGAGGAGGTGAT & 18 & \multirow{2}{*}{111} \\
\hline MEG3-R & GGAGTGCTGTTGGAGAATA & 19 & \\
\hline SPRY4-IT1-F & AGCCACATAAATTCAGCAGA & 20 & \multirow{2}{*}{115} \\
\hline SPRY4-IT1-R & GATGTAGGATTCCTTTCA & 18 & \\
\hline HOXA-AS2-F & CCCGTAGGAAGAACCGATGA & 20 & \multirow{2}{*}{70} \\
\hline HOXA-AS2-R & TTTAGGCCTTCGCAGACAGC & 20 & \\
\hline Linc-ROR-F & \begin{tabular}{|l|} 
TATAATGAGATACCACCTTA \\
\end{tabular} & 20 & \multirow{2}{*}{170} \\
\hline Linc-ROR-R & AGGAACTGTCATACCGTTTC & 20 & \\
\hline UCA1-F & CTTAGGCTGGCAACCATCAGATCC & 24 & \multirow{2}{*}{129} \\
\hline UCA1-R & GTGTTGTCCTGCATGCTGGTCTG & 23 & \\
\hline MALAT1-F & GACGGAGGTTGAGATGAAGC & 20 & \multirow{2}{*}{84} \\
\hline MALAT1-R & ATTCGGGGCTCTGTAGTCCT & 20 & \\
\hline B2M-F & AGATGAGTATGCCTGCCGTG & 20 & \multirow{2}{*}{105} \\
\hline B2M-R & GCGGCATCTTCAAACCTCCA & 20 & \\
\hline
\end{tabular}

Table 1. Sequences of primers used in the study.

antisense to the human HOXA3 and HOXA4 genes ${ }^{8}$. Considering the role of HOXA genes in the process of neurodevelopment $^{9}$ and the role of abnormal brain development in the pathogenesis of schizophrenia ${ }^{10}, H O X A-A S 2$ might be involved in this psychiatric disorder. The long intergenic non-protein coding RNA, regulator of reprogramming (Linc-ROR) controls the reprogramming of pluripotent stem cells ${ }^{11}$ and is regarded as an inhibitor of p53 tumor suppressor ${ }^{12}$, a gene which has been believed to contribute in schizophrenia for a long time ${ }^{13}$. The maternally expressed gene 3 (MEG3) regulates expression of AMPA glutamate receptor in primary cortical neurons ${ }^{14}$. Based on the reported abnormalities in the glutaminergic system in schizophrenia ${ }^{15}, M E G 3$ is another putative lncRNA in the pathogenesis of schizophrenia. The SPRY4 intronic transcript 1 (SPRY4-IT1) regulates levels of lipin 2 , a protein that facilitates conversion of phosphatidate to diacylglyceroland. SPRY4-IT1 possibly participates in lipid biosynthesis as its silencing leads to lipotoxicity ${ }^{16}$. Considering the observed associations between altered lipid profile and occurrence of schizophrenia ${ }^{17}$, SPRY4-IT1 might be involved in this disorder. The urothelial cancer associated 1 (UCA1) has an established role in neurons as it suppresses apoptosis of hippocampal neurons via miR-495/Nrf2-ARE pathway ${ }^{18}$. Moreover, this $\operatorname{lncRNA}$ contributes in inhibition of hypoxia injury after cerebral ischemia ${ }^{19}$. As schizophrenia is known as "an adult vascular-ischemic disorder" 20 , UCA1 might affect the course of this disorder. Finally, Metastasis Associated Lung Adenocarcinoma Transcript 1 (MALAT1) is abundantly expressed in neurons and is enriched in nuclear speckles in a transcription-dependent manner., MALAT1 participates in the regulation of synaptogenesis-related genes in vitro ${ }^{21}$. Besides, its silencing has decreased synaptic density in cultured hippocampal neurons ${ }^{21}$, a finding that potentiates this lncRNA as a modulating agent in the course of schizophrenia based on the reported decrease in synaptophysin in hippocampus and frontal cortical areas of patients with schizophrenia ${ }^{22}$. Consequently, dysregulation of the selected lncRNAs might be involved in the schizophrenia pathogenesis or applied as disease biomarkers.

\section{Material and Methods}

Study participants. The current study was performed in 60 patients with schizophrenia (39 male patients and 21 female patients, mean age \pm standard deviation: $49.63 \pm 9.64)$ and 60 healthy subjects (47 male patients and 13 female patients, mean age \pm standard deviation: $49.48 \pm 11.94)$. Patients were referred to psychiatry departments of Shahid Beheshti and Hamadan Universities of Medical Sciences. Patients were diagnosed according to the fifth edition of Diagnostic and Statistical Manual of Mental Disorders (DSM-V $)^{1}$. Patients with schizophrenia were taking standard dose of Clozapine ${ }^{\mathrm{TM}}$ (301 mg/day to $600 \mathrm{mg} /$ day). Inclusion criteria were compliance with the diagnostic criteria and patients' willingness for participation in the study. Exclusion criteria were substance abuse, cigarette smoking or use of other antipsychotic drugs. Persons enlisted as controls were assessed through a structured psychiatric interview (Mini-International Neuropsychiatric Interview ${ }^{23}$ ), for excluding the presence of psychiatric disorders. Exclusion criteria were the presence of malignancy, recent or continuous infectious disorder, autoimmune conditions, nerve muscle coupling disorders and pregnancy. The study protocol was approved by Ethical Committee of Shahid Beheshti University of Medical Sciences and all methods were performed in accordance with the relevant guidelines and regulations. Informed written consent forms were signed by all study participants.

Expression study. Total RNA was isolated from venous blood of enrolled individuals using Hybrid-RTM blood RNA extraction Kit (GeneAll Biotechnology Co. Ltd., Seoul, South Korea). The quality and quantity of RNA was appraised using Nanodrop equipment (Thermo Scientific, MA, USA). Subsequently, cDNA was produced using FIREScript RT cDNA Synthesis Kit (Solis BioDyne, Estonia). Relative expressions of lncRNAs were assessed in patients with schizophrenia and controls using RealQ Plus Master Mix Green (AMPLICON, Denmark) in the rotor gene 6000 Real-Time PCR System (Corbett, Australia). B2M gene was used as the normalizer. The sequences of primers and amplicon lengths are shown in Table 1. 


\begin{tabular}{|c|c|c|c|}
\hline Study groups & Parameters & & \begin{tabular}{|l|} 
Values \\
\end{tabular} \\
\hline \multirow{11}{*}{ Patients } & \multirow{2}{*}{ Sex (number) } & Male & 39 \\
\hline & & Female & 21 \\
\hline & \multirow{2}{*}{ Age (Years, mean $\pm \mathrm{SD}$ (range)) } & Male & $51.25 \pm 10.38(32-79)$ \\
\hline & & Female & $46.61 \pm 7.37(31-61)$ \\
\hline & \multirow{2}{*}{ Age at onset (Years, mean $\pm \mathrm{SD}$ (range)) } & Male & $34.94 \pm 1.86(29-39)$ \\
\hline & & Female & $35.09 \pm 2.47(29-40)$ \\
\hline & \multirow{2}{*}{ Duration (Years, mean $\pm \mathrm{SD}$ (range)) } & Male & $16.73 \pm 9.55(1-46)$ \\
\hline & & Female & $11.52 \pm 6.08(1-22)$ \\
\hline & \multirow{3}{*}{ Education (\%) } & Preschool & $30 \%$ \\
\hline & & School & $48.3 \%$ \\
\hline & & University & $21.7 \%$ \\
\hline \multirow{7}{*}{ Controls } & \multirow{2}{*}{ Sex (number) } & Male & 47 \\
\hline & & Female & 13 \\
\hline & \multirow{2}{*}{ Age (Years, mean $\pm \mathrm{SD}$ (range)) } & Male & $50 \pm 12.75(25-77)$ \\
\hline & & Female & $49.63 \pm 8.58(34-61)$ \\
\hline & \multirow{3}{*}{ Education (\%) } & Preschool & $11.6 \%$ \\
\hline & & School & $26.7 \%$ \\
\hline & & University & $61.7 \%$ \\
\hline
\end{tabular}

Table 2. General data of study participants.

Statistical methods. Expressions of lncRNAs in each sample were calculated using the Efficiency ${ }^{\wedge \mathrm{Ct}}$ normalizer gene-Efficiency ${ }^{\wedge} \mathrm{CT}$ target gene method. The Statistical Package for the Social Sciences (SPSS) v.18.0 (SPSS Inc., Chicago, IL) was used for statistical assessments. The correlations between transcript levels of lncRNAs were evaluated using regression model and Bonferroni correction for multiple comparisons. The correlation between expression levels and age of study participants was described by $\mathrm{R}$ and $\mathrm{P}$ values. Mean values of gene expression were compared between education-based subgroups of patients and controls using one-way ANOVA and Tukey post hoc tests. For all statistical tests, the level of significance was set at $\mathrm{P}<0.05$. The receiver operating characteristic (ROC) curves were depicted to appraise the diagnostic power of expression levels of lncRNAs.

\section{Results}

General data of study participants. The available data of study participants are summarized in Table 2 .

When comparing expression of lncRNAs in total patients and total controls, HOXA-AS2, Linc-ROR, MEG3, SPRY4-IT1 and UCA 1 were significantly over-expressed in patients. However, when evaluating expression of genes in sex-based subgroups, the differences in the expression of these lncRNAs were significant only among females. Table 3 shows the expression ratios and $\mathrm{P}$ values of comparison of genes expressions between groups. Figure 1 depicts the -delta Ct values of lncRNAs in patients and controls.

Correlation between expression of IncRNAs and age of study participants. Assessment of partial correlation between expression of lncRNAs and age of study participants after controlling the effect of sex, revealed significant correlations for HOXA-AS2, MALAT1 and UCA1 in both patients and controls. Besides, expressions of Linc-ROR and SPRY4-IT1 were correlated with age only in patients. Expressions of HOXA-AS2, $M E G 3$ and $U C A 1$ were correlated with age at disease onset in patients with schizophrenia. Moreover, expressions of MALAT1 and UCA 1 were correlated with disease duration in these patients. Table 4 shows the results of partial correlation between expression of lncRNAs and age.

Correlation between expression levels of IncRNAs. Significant pairwise correlations were recognized between expression levels of lncRNAs in both patients with schizophrenia and controls (Table 5).

Association between expression level of genes and education level. We compared mean values of gene expression between education-based subgroups of patients and controls using one-way ANOVA test. The results of Tukey post hoc test showed significant difference in SPRY4-IT1 expression between preschool and school groups in normal individuals. Expressions of other genes were not different between education-based subgroups of either patients or controls (Table 6).

ROC curve analysis. Based on the results of sex-based analysis and similar expression of genes between male patients and male controls, ROC curves were depicted only for female subjects (Fig. 2).

Table 7 shows the detailed information of ROC curve analysis. Based on the area under curve (AUC) values, SPRY4-IT1 had the best performance in differentiation of female patients from female controls (AUC $=0.85$, $\mathrm{P}<0.0001$ ). Combination of Linc-ROR, MEG3, SPRY4-IT1 and UCA1 expression levels could differentiate female patients with $95.2 \%$ sensitivity, $76.9 \%$ specificity and diagnostic power of $0.88(\mathrm{P}<0.0001)$. 


\begin{tabular}{|l|l|l|l|l|}
\hline \multicolumn{2}{|c|}{} & $\begin{array}{l}\text { Total patients vs. } \\
\text { controls (60 vs. 60) }\end{array}$ & $\begin{array}{l}\text { Male patients vs. male } \\
\text { controls (39 vs. 47) }\end{array}$ & $\begin{array}{l}\text { Female patients vs. female } \\
\text { controls (21 vs. 13) }\end{array}$ \\
\hline \multirow{2}{*}{ HOXA-AS2 } & Expression ratio & 2.88 & 1.28 & 12.84 \\
\cline { 2 - 5 } & P-value & 0.04 & 0.7 & 0.03 \\
\hline \multirow{2}{*}{ Linc-ROR } & Expression ratio & 4.44 & 1.4 & 53.07 \\
\cline { 2 - 5 } & P-value & 0.008 & 0.55 & 0.005 \\
\hline \multirow{2}{*}{ MALAT1 } & Expression ratio & 1.42 & 0.82 & 3.64 \\
\cline { 2 - 5 } & P-value & 0.34 & 0.53 & 0.12 \\
\hline \multirow{2}{*}{ MEG3 } & Expression ratio & 3.17 & 1.27 & 18.93 \\
\cline { 2 - 6 } & P-value & 0.02 & 0.67 & 0.01 \\
\hline \multirow{2}{*}{ SPRY4-IT1 } & Expression ratio & 6.24 & 1.87 & 87.14 \\
\cline { 2 - 5 } & P-value & 0.001 & 0.3 & $<.001$ \\
\hline \multirow{2}{*}{ CA1 } & Expression ratio & 4.16 & 1.63 & 0.009 \\
\cline { 2 - 5 } & P-value & 0.006 & 0.34 & \\
\hline
\end{tabular}

Table 3. The results of expression study of lncRNAs in peripheral blood of patients with schizophrenia compared with controls (The statistical power values for comparison between female cases and female controls as computed by Post Hoc analysis are 86\% (HOXA-AS2), 99.6\% (Linc-ROR), 60\% (MALAT1), 97.4\% (MEG3), 98.7\% (SPRY4-IT1) and 98.6\% (UCA1) respectively).

\begin{tabular}{|c|c|c|c|c|c|c|c|c|c|c|c|c|c|}
\hline \multirow{2}{*}{$\begin{array}{l}\text { Study } \\
\text { groups }\end{array}$} & \multirow[b]{2}{*}{ Parameters } & \multicolumn{2}{|c|}{ HOXA-ASI } & \multicolumn{2}{|c|}{ Linc-ROR } & \multicolumn{2}{|c|}{ MALAT1 } & \multicolumn{2}{|c|}{ MEG3 } & \multicolumn{2}{|c|}{ SPRY4-IT1 } & \multicolumn{2}{|c|}{ UCA1 } \\
\hline & & $\mathbf{R}$ & P value & $\mathbf{R}$ & P value & $\mathbf{R}$ & $P$ value & $\mathbf{R}$ & P value & $\mathbf{R}$ & P value & $\mathbf{R}$ & Pvalue \\
\hline \multirow{3}{*}{ Patients } & Age & 0.27 & 0.02 & 0.25 & 0.03 & 0.27 & 0.02 & 0.2 & 0.06 & 0.22 & 0.04 & 0.4 & 0.001 \\
\hline & Age at onset & 0.28 & 0.01 & 0.16 & 0.11 & 0.18 & 0.08 & 0.23 & 0.04 & 0.17 & 0.1 & 0.32 & 0.007 \\
\hline & Disease duration & 0.2 & 0.07 & 0.02 & 0.07 & 0.21 & 0.03 & 0.12 & 0.18 & 0.16 & 0.11 & 0.33 & 0.006 \\
\hline Controls & Age & 0.37 & 0.002 & 0.07 & 0.3 & 0.32 & 0.007 & 0.16 & 0.1 & 0.15 & 0.12 & 0.25 & 0.03 \\
\hline
\end{tabular}

Table 4. The results of partial correlation between expression of lncRNAs and age (controlled for sex).

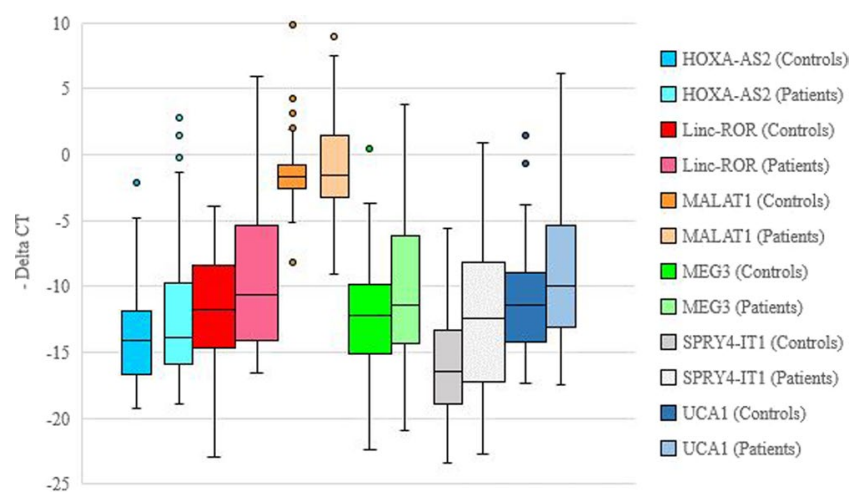

Figure 1. Relative expression of lncRNAs in patients with schizophrenia and controls as described by - delta Ct values (Ct Housekeeping gene- Ct Target gene).

\section{Discussion}

In the current investigation, we reported significant up-regulation of HOXA-AS2, Linc-ROR, MEG3, SPRY4-IT1 and $U C A 1$ in female patients compared with female normal subjects. However, expression levels of none of lncRNAs were different between male patients and male controls. The sex-based alterations have been noted previously in age of onset, course, and treatment response in patients with schizophrenia ${ }^{24}$. In addition, differences in neurodevelopmental processes and psychosocial parameters ${ }^{24}$ and increase in brain gene expression divergence in males have been associated with risk of schizophrenia ${ }^{25}$. The observed sex-based differences in the expression of lncRNAs in the current study might reflect the presences of hormone-response elements in the mentioned lncRNAs. Such elements have been noted in some $\operatorname{lncRNAs}$ such as GAS5 ${ }^{26}$. Moreover, several $\operatorname{lncRNAs}$ are involved in germ cell specification, sex determination and sex hormone responses ${ }^{27}$. Two previously appreciated mechanisms for the observed sex-based differences in human diseases are gonadal sex hormones or the sex chromosomes ${ }^{28}$. The current study and similar studies in neuropsychiatric disorders ${ }^{29}$ provide preliminary evidences for contribution of lncRNAs in this process. However, further studies are required to appraise whether this effect is exerted through interaction with the previously appraised mechanisms or is performed independently. 


\begin{tabular}{|l|l|l|l|l|l|l|}
\hline \multicolumn{2}{|c|}{} & UCA1 & SPRY4-IT1 & MEG3 & MALAT1 & Linc-ROR \\
\hline \multirow{3}{*}{ HOXA-AS2 } & Controls & $0.4^{*}$ & $0.21^{*}$ & $0.31^{*}$ & $0.26^{*}$ & 0.1 \\
\cline { 2 - 8 } & Patients & $0.5^{*}$ & $0.5^{*}$ & $0.62^{*}$ & $0.5^{*}$ & $0.68^{*}$ \\
\hline \multirow{2}{*}{ Linc-ROR } & Controls & $0.22^{*}$ & 0.14 & $0.19^{*}$ & 0.12 & \\
\cline { 2 - 8 } & Patients & $0.31^{*}$ & $0.57^{*}$ & $0.6^{*}$ & $0.37^{*}$ & \\
\hline \multirow{2}{*}{ MALAT1 } & Controls & $0.22^{*}$ & $0.2^{*}$ & 0.18 & & \\
\cline { 2 - 8 } & Patients & $0.31^{*}$ & $0.26^{*}$ & $0.32^{*}$ & & \\
\hline \multirow{2}{*}{ SPRY4-IT1 } & Controls & $0.24^{*}$ & $0.21^{*}$ & & & \\
\cline { 2 - 8 } & Patients & $0.36^{*}$ & $0.48^{*}$ & & & \\
\cline { 2 - 8 } & Controls & $0.24^{*}$ & & & & \\
\hline
\end{tabular}

Table 5. Correlations between expressions of lncRNAs in study groups ( $\mathrm{R}^{2}$ values are presented; after correction for multiple comparisons (Bonferroni correction), $\mathrm{P}$ value less than 0.0016 was accepted as significant (marked by*)).

\begin{tabular}{|c|c|c|c|c|c|c|c|c|}
\hline \multirow[b]{2}{*}{ Genes } & \multicolumn{4}{|l|}{ Controls } & \multicolumn{4}{|l|}{ Patients } \\
\hline & \begin{tabular}{|l|} 
Preschool \\
\end{tabular} & School & University & Pvalue & Preschool & \begin{tabular}{|l|} 
School \\
\end{tabular} & University & Pvalue \\
\hline HOXA-AS1 & $15.22 \pm 3.09$ & $13.17 \pm 4.33$ & $13.84 \pm 3.5$ & 0.47 & $12.44 \pm 5.8$ & $11.9 \pm 6.3$ & $11.9 \pm 5.37$ & 0.95 \\
\hline Linc-ROR & $13.01 \pm 5.63$ & $11.93 \pm 4.41$ & $11.58 \pm 4.35$ & 0.74 & $8.86 \pm 6.79$ & $9.25 \pm 5.82$ & $9.96 \pm 5.63$ & 0.88 \\
\hline MALAT1 & $3.38 \pm 2.83$ & $1.32 \pm 2.11$ & $1.03 \pm 2.88$ & 0.11 & $-0.26 \pm 3.6$ & $1.32 \pm 4.25$ & $1.26 \pm 4.37$ & 0.4 \\
\hline MEG3 & $12.8 \pm 3.51$ & $11.4 \pm 5.32$ & $12.44 \pm 3.97$ & 0.67 & $10.64 \pm 7.18$ & $9.98 \pm 5.07$ & $10.19 \pm 5.5$ & 0.93 \\
\hline SPRY4-IT1 & $18.82 \pm 2.46$ & $14.15 \pm 4.55$ & $15.77 \pm 4.02$ & 0.04 & $13.04 \pm 5.34$ & $12.33 \pm 6.09$ & $12.36 \pm 5.07$ & 0.9 \\
\hline UCA1 & $12.44 \pm 3.12$ & $10.36 \pm 3.69$ & $11.41 \pm 4.32$ & 0.49 & $10.35 \pm 4.3$ & $8.18 \pm 5.8$ & $8.05 \pm 6.05$ & 0.36 \\
\hline
\end{tabular}

Table 6. Mean values ( \pm standard deviation) of gene expressions in different subgroups of patients and controls. Study participants are stratified based on their higher level of education.

\begin{tabular}{|l|l|l|l|l|l|c|}
\hline & $\begin{array}{l}\text { Estimate } \\
\text { criterion }\end{array}$ & AUC & J & Sensitivity & Specificity & P-value \\
\hline Linc-ROR & $\leq 11.2$ & 0.78 & 0.5 & 81 & 69.2 & 0.0006 \\
\hline MEG3 & $\leq 11.5$ & 0.74 & 0.41 & 71.4 & 69.2 & 0.005 \\
\hline SPRY4-IT1 & $\leq 12.9$ & 0.85 & 0.75 & 90.5 & 84.6 & $<0.0001$ \\
\hline UCA1 & $\leq 12.1$ & 0.8 & 0.58 & 81 & 76.9 & 0.0005 \\
\hline $\begin{array}{l}\text { Combination of all } \\
\text { genes }\end{array}$ & $>0.46$ & 0.88 & 0.73 & 95.2 & 77 & $<0.0001$ \\
\hline
\end{tabular}

Table 7. The results of ROC curve analysis in female subjects.

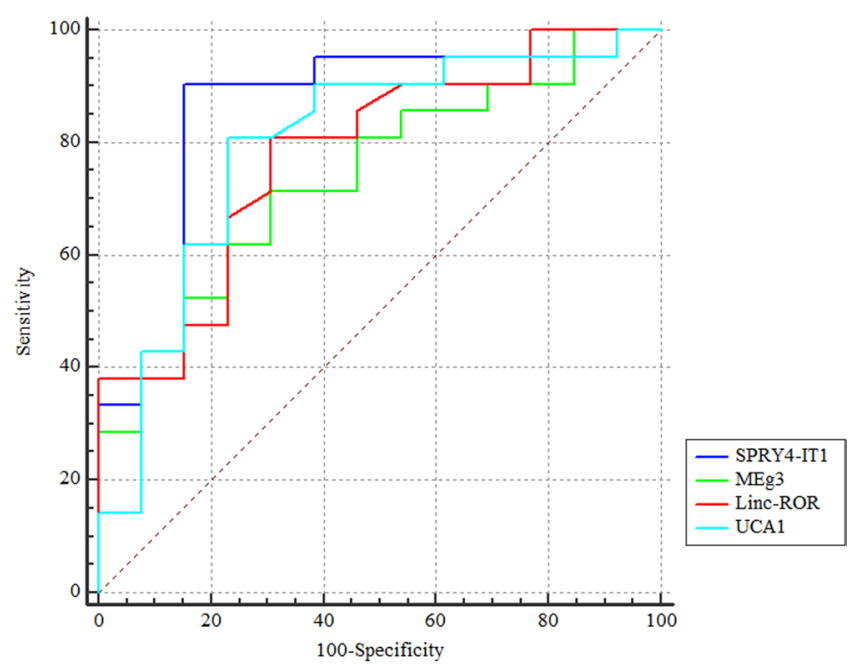

Figure 2. ROC curves of lncRNAs transcript levels in female subjects. 
Although males are expected to be affected with earlier onset and more severe disease course ${ }^{30}$, our findings revealed similar expression of lncRNAs between male patients and male controls. This finding possibly rules out the participation of these lncRNAs in the pathogenesis of schizophrenia in male subjects. Moreover, this observation is consistent with the results of our recent study where we reported significant associations between expression levels of GAS5, NEAT1 and OIP5-AS1 lncRNAs and schizophrenia in female subjects but not in male individuals ${ }^{31}$. The sharp sex-based contrasts in expression signatures of lncRNAs might imply the sex-specific roles for these lncRNAs. A recent study has revealed a sex-biased lncRNA signature in placenta ${ }^{32}$. Moreover, co-expression assessments have demonstrated several lncRNAs correlation with sex differences in mouse germline stem cells ${ }^{33}$. The importance of the observed sex-based differences in lncRNA patter in patients with schizophrenia is more highlighted when considering the extensive sex differences in gene signature in the adult human brain. Moreover, several genes with sex-biased expression are associated with diseases and possibly have functional significances. Taken together, such sex-biased expression implies the presence of sex-biased gene regulatory mechanisms ${ }^{34}$.

HOXA-AS2 has been shown to interact with the enhancer of zeste homolog 2 (EZH2). EZH2 has crucial roles in the epigenetic silencing of cyclooxygenase- $2^{35}$, an enzyme whose over-expression has been noted in schizophrenia as a result of immune response dysregulation ${ }^{36}$. Moreover, analysis of RNA-seq data has shown a significant elevation in EZH2 levels in the anterior cingulate cortex of patients with schizophrenia compared to normal individuals. Based on these results, Billingsley et al. have suggested a role for EZH2 in schizophrenia. Such role might be exerted either through interference with normal brain development or through abnormal reactivation of expression in the CNS in the adulthood ${ }^{37}$. Future studies are necessary to find the interactions between HOXA-AS2, EZH2 and cyclooxygenase- 2 in the context of schizophrenia.

Linc-ROR has been shown to act as a sponge for miR-138 and miR-145 ${ }^{38}$. miR-138 has a regulatory role in dendritic spine morphogenesis ${ }^{39}$, a process that is dysregulated in schizophrenia ${ }^{40}$. miR-145 has a functional role in the brain tissue as its over-expression alleviates astrocyte damage in cerebral ischemic stroke ${ }^{41}$. This miRNA targets Aquaporin $4^{41}$, a gene whose polymorphisms are associated with negative symptoms of schizophrenia ${ }^{42}$. So, it is plausible that $L i n c-R O R$ participates in the pathogenesis of schizophrenia through modulation of miR-145 and subsequent alterations in Aquaporin 4. In addition, this lncRNA might affect schizophrenia through alterations in dendritic spine morphogenesis.

Elevated levels of MEG3 have been reported in in the nucleus accumbens of heroin abusers ${ }^{43}$. Heroine influences dopaminergic, glutamatergic and GABAergic routes that participate in the pathogenesis of schizophrenia ${ }^{44}$. Consequently, it is possible that MEG3 also affects the mentioned transmitters and participates in the evolution of schizophrenia.

Over-expression of SPRY4-IT1 has been shown to induce EZH $2^{45}$, a transcription factor that is over-expressed in the anterior cingulate cortex of patients with schizophrenia compared to controls and has been suggested to participate in the schizophrenia either via interference with developmental processes or through abnormal reactivation of gene expression in the adult brain ${ }^{37}$. This lncRNA might also contribute in schizophrenia through alteration of lipid profiles. Moreover, it is worth mentioning that both SPRY4-IT1 and HOXA-AS2 are partners of EZH2. So, dysregulation of these lncRNAs might have synergic effects on the aberrant expression of EZH2 in patients with schizophrenia.

UCA1 is an lncRNA with regulatory roles on the $\mathrm{Wnt} / \beta$ catenin pathway ${ }^{46}$, a pathway that is highly dysregulated in peripheral blood of patients with schizophrenia ${ }^{47}$. Consequently, the observed over-expression of this lncRNA might participate in the pathogenesis of schizophrenia through alterations in Wnt/ $\beta$ catenin pathway. However, such expression pattern is not consistent with the proposed role for this lncRNA in protection against hypoxia $^{19}$.

We also demonstrated significant correlations between age and expression of the lncRNAs HOXA-AS2, MALAT1 and UCA 1 in both patients and controls. Besides, expressions of Linc-ROR and SPRY4-IT1 were correlated with age only in patients. Such correlations might imply the role of age in determination of expression levels of these lncRNAs. This speculation is consistent with the results of a recent study which demonstrated an age-dependent diurnal expression of lncRNAs which concurs with age-related alterations in facultative heterochromatin $^{48}$. We also reported correlations between expressions of HOXA-AS2, MEG3 and UCA1 and age at disease onset in patients with schizophrenia. Moreover, expressions of MALAT1 and UCA1 were correlated with disease duration in these patients. Such correlations might reflect the effects of disease course or antipsychotic treatments on genes expression. Alternatively, they might merely show the age-related mechanisms. Decisive results can be only obtained from larger-scale cohorts of patients with different age ranges and disease duration values.

We also demonstrated several pairwise correlations between expression of lncRNAs in both normal individuals and patients with schizophrenia which suggest their regulation by a similar possibly epigenetic mechanism or their involvement in similar cellular processes. Clues for the second possibility have been obtained for SPRY4-IT1 and HOXA-AS2 as both are EZH2 partners.

Finally, we reported the suitability of a panel of lncRNAs for discrimination of female patients with schizophrenia from normal female individuals. If these results are verified in larger sample sizes, the suggested panel might be used as a diagnostic panel for schizophrenia.

Taken together, our results imply contribution of certain lncRNAs in the pathogenesis of schizophrenia in female subjects and suggest them as elements of a diagnostic panel. However, our study has some limitations including lack of body mass index (BMI) and the Positive and Negative Syndrome Scale (PANSS) score of study participants and unavailability of drug-naïve patients. Although the effect of Clozapine on gene expression cannot be ruled out without analyses of expression profile of drug-naïve patients, a previous study has indicated that Clozapine monotherapy might induce only minor alterations in gene expression ${ }^{49}$. By excluding patients who used other antipsychotic drugs, we have minimized the confounding factors. 


\section{References}

1. Association D-AP. Diagnostic and statistical manual of mental disorders. Arlington: American Psychiatric Publishing (2013).

2. Narayan, S. et al. Molecular profiles of schizophrenia in the CNS at different stages of illness. Brain research. 1239, 235-48. PubMed PMID: 18778695. Pubmed Central PMCID: PMC2783475. Epub 2008/09/10. eng (2008 Nov 6).

3. Roy, M. et al. Proteomic analysis of postsynaptic proteins in regions of the human neocortex. Nature neuroscience. PubMed PMID: 29203896. Epub 2017/12/06. eng. 21(1), 130-8 (2018 Jan).

4. Ramaker, R. C. et al. Post-mortem molecular profiling of three psychiatric disorders. Genome medicine. PubMed PMID: 28754123. Pubmed Central PMCID: PMC5534072. Epub 2017/07/30. eng., 9(1), 72 (2017 Jul 28).

5. Long, Y., Wang, X., Youmans, D. T. \& Cech, T. R. How do lncRNAs regulate transcription? Science advances. PubMed PMID: 28959731. Pubmed Central PMCID: PMC5617379. Epub 2017/09/30. eng. 3(9), eaao2110 (2017 Sep).

6. Lai, C. Y. et al. Biomarkers in schizophrenia: A focus on blood based diagnostics and theranostics. World J Psychiatr. PubMed PMID: WOS:000408779400009. English, 6(1), 102-17 (2016 Mar 22).

7. Hu J et al. Systematically characterizing dysfunctional long intergenic non-coding RNAs in multiple brain regions of major psychosis. Oncotarget. PubMed PMID: 27661005. Pubmed Central PMCID: PMC5342065. Epub 2016/09/24. eng. 7(44), 71087-98 (2016 Nov 1).

8. Zhao, H., Zhang, X., Frazão, J. B., Condino-Neto, A. \& Newburger, P. E. HOX antisense lincRNA HOXA-AS2 is an apoptosis repressor in all Trans retinoic acid treated NB4 promyelocytic leukemia cells. Journal of cellular biochemistry. 114(10), 2375-83 (2013).

9. Nolte, C \& Krumlauf, R. Expression of Hox genes in the nervous system of vertebrates. HOX gene expression: Springer, p. 14-41 (2007).

10. Arnold, S. E. Neurodevelopmental abnormalities in schizophrenia: insights from neuropathology. Development and psychopathology. Summer 11(3), 439-56. PubMed PMID: 10532618. Epub 1999/10/26. eng (1999).

11. Loewer, S. et al. Large intergenic non-coding RNA-RoR modulates reprogramming of human induced pluripotent stem cells. Nature genetics 42(12), 1113-7. PubMed PMID: 21057500. Pubmed Central PMCID: PMC3040650. Epub 2010/11/09. eng (2010 Dec).

12. Zhang, A. et al. The human long non-coding RNA-RoR is a p53 repressor in response to DNA damage. Cell research. 23(3), 340-50. PubMed PMID: 23208419. Pubmed Central PMCID: PMC3587705. Epub 2012/12/05. eng (2013 Mar).

13. Ni, X. et al. Human p53 tumor suppressor gene (TP53) and schizophrenia: case-control and family studies. Neuroscience letters. 388(3), 173-8. PubMed PMID: 16039051. Epub 2005/07/26. eng (2005 Nov 18).

14. Tan, M. C. et al. The Activity-Induced Long Non-Coding RNA Meg3 Modulates AMPA Receptor Surface Expression in Primary Cortical Neurons. Frontiers in cellular neuroscience. 11, 124. PubMed PMID: 28515681. Pubmed Central PMCID: PMC5413565. Epub 2017/05/19. eng (2017).

15. Rubio, M. D., Drummond, J. B. \& Meador-Woodruff, J. H. Glutamate Receptor Abnormalities in Schizophrenia: Implications for Innovative Treatments. Biomol Ther. 20(1), 1-18. PubMed PMID: WOS:000300469100001. English (2012 Jan 31).

16. Mazar, J. et al. The Functional Characterization of Long Noncoding RNA SPRY4-IT1 in Human Melanoma Cells. Oncotarget. 5(19), 8959-69. PubMed PMID: WOS:000348033800011. English (2014 Oct 15).

17. Oresic, M. et al. Phospholipids and insulin resistance in psychosis: a lipidomics study of twin pairs discordant for schizophrenia. Genome medicine. 4(1), 1. PubMed PMID: 22257447. Pubmed Central PMCID: PMC3334549. Epub 2012/01/20. eng (2012 Jan 18).

18. Geng, J. F. et al. LncRNA UCA1 inhibits epilepsy and seizure-induced brain injury by regulating miR-495/Nrf2-ARE signal pathway. The international journal of biochemistry \& cell biology. 99, 133-9 PubMed PMID: 29608952. Epub 2018/04/03. eng (2018 Jun).

19. Tian, J. et al. Roles of IncRNA UCA1-miR-18a-SOX6 axis in preventing hypoxia injury following cerebral ischemia. International. Journal of Clinical \& Experimental Pathology. 10, 8187-98 (2017).

20. Moises, H., Wollschläger, D. \& Binder, H. Functional genomics indicate that schizophrenia may be an adult vascular-ischemic disorder. Translational psychiatry. 5(8), e616 (2015).

21. Bernard, D. et al. A long nuclear-retained non-coding RNA regulates synaptogenesis by modulating gene expression. The $E M B O$ journal. 29(18), 3082-93 (2010).

22. Osimo, E. F., Beck, K., Marques, T. R. \& Howes, O. D. Synaptic loss in schizophrenia: a meta-analysis and systematic review of synaptic protein and mRNA measures. Mol Psychiatr. 24(4), 549-61 PubMed PMID: WOS:000461902000008. English (2019 Apr).

23. Sheehan, D. V. et al. The Mini-International Neuropsychiatric Interview (M.I.N.I.): the development and validation of a structured diagnostic psychiatric interview for DSM-IV and ICD-10. J Clin Psychiatry. 59(Suppl 20), 22-33;quiz 4-57. PubMed PMID: 9881538. Epub 1999/01/09. eng (1998).

24. Leung, A \& Chue, P. Sex differences in schizophrenia, a review of the literature. Acta psychiatrica Scandinavica Supplementum. PubMed PMID: 10887978. Epub 2000/07/11. eng, 401, 3-38 (2000).

25. Chen, J. F., Cao, H., Meyer-Lindenberg, A. \& Schwarz, E. Male increase in brain gene expression variability is linked to genetic risk for schizophrenia. Translational Psychiatry. 8 PubMed PMID: WOS:000440624500001. English (2018 Aug 1).

26. Pickard, M. R. \& Williams, G. T. The hormone response element mimic sequence of GAS5 lncRNA is sufficient to induce apoptosis in breast cancer cells. Oncotarget. 7(9), 10104-16. PubMed PMID: 26862727. Pubmed Central PMCID: PMC4891107. Epub 2016/02/11. eng (2016 Mar 1).

27. Taylor, D. H., Chu, E. T., Spektor, R. \& Soloway, P. D. Long non-coding RNA regulation of reproduction and development. Molecular reproduction and development. 82(12), 932-56. PubMed PMID: 26517592. Pubmed Central PMCID: 4762656 (2015 Dec).

28. Snell, D. M. \& Turner, J. M. A. Sex Chromosome Effects on Male-Female Differences in Mammals. Curr Biol. 28(22), R1313-R24. PubMed PMID: 30458153. Pubmed Central PMCID: PMC6264392. Epub 2018/11/21. eng (2018 Nov 19).

29. Sayad, A. et al. Peripheral expression of long non-coding RNAs in bipolar patients. Journal of affective disorders. 249, 169-74. PubMed PMID: 30772744 (2019 Apr 15).

30. Messias, E. L., Chen, C. Y. \& Eaton, W. W. Epidemiology of schizophrenia: review of findings and myths. The Psychiatric clinics of North America. 30(3), 323-38. PubMed PMID: 17720026. Pubmed Central PMCID: PMC2727721. Epub 2007/08/28. eng (2007 Sep).

31. Safari, M. R., Komaki, A., Arsang-Jang, S, Taheri, M \& Ghafouri-Fard, S. Expression Pattern of Long Non-coding RNAs in Schizophrenic Patients. Cellular and molecular neurobiology. 39(2), 211-21. PubMed PMID: 30560506. Epub 2018/12/19. eng (2019 Mar).

32. Majewska, M. et al. Preliminary RNA-Seq Analysis of Long Non-Coding RNAs Expressed in Human Term Placenta. Int J Mol Sci. 19(7). PubMed PMID: WOS:000442807400073. English (2018 Jul).

33. Li, X., Ao, J. \& Wu, J. Systematic identification and comparison of expressed profiles of lncRNAs and circRNAs with associated coexpression and ceRNA networks in mouse germline stem cells. Oncotarget. 8(16), 26573-90. PubMed PMID: 28404936. Pubmed Central PMCID: 5432280 (2017 Apr 18).

34. Trabzuni, D. et al. Widespread sex differences in gene expression and splicing in the adult human brain. Nature communications. 4, 2771. PubMed PMID: 24264146. Pubmed Central PMCID: PMC3868224. Epub 2013/11/23. eng (2013).

35. Coward, W. R., Feghali-Bostwick, C. A., Jenkins, G., Knox, A. J. \& Pang, L. A central role for G9a and EZH2 in the epigenetic silencing of cyclooxygenase-2 in idiopathic pulmonary fibrosis. FASEB journal: official publication of the Federation of American Societies for Experimental Biology. 28(7), 3183-96. PubMed PMID: 24652950. Pubmed Central PMCID: PMC4062820. Epub 2014/03/22. eng (2014 Jul). 
36. Muller, N. \& Schwarz, M. J. COX-2 inhibition in schizophrenia and major depression. Current pharmaceutical design. 14(14), 1452-65. PubMed PMID: 18537668. Epub 2008/06/10. eng (2008).

37. Billingsley, K. J. et al. Regulatory characterisation of the schizophrenia-associated CACNA1C proximal promoter and the potential role for the transcription factor EZH2 in schizophrenia aetiology. Schizophrenia research. PubMed PMID: 29501388. Pubmed Central PMCID: 6179964, 199, 168-75 (2018 Sep).

38. Feng, L. et al. Linc-ROR Promotes Osteogenic Differentiation of Mesenchymal Stem Cells by Functioning as a Competing Endogenous RNA for miR-138 and miR-145. Molecular therapy Nucleic acids. 11, 345-53. PubMed PMID: 29858070. Pubmed Central PMCID: PMC5992460. Epub 2018/06/03. eng (2018 Jun 1).

39. Siegel, G. et al. A functional screen implicates microRNA-138-dependent regulation of the depalmitoylation enzyme APT1 in dendritic spine morphogenesis. Nature cell biology. 11(6), 705-16. PubMed PMID: 19465924. Pubmed Central PMCID: PMC3595613. Epub 2009/05/26. eng (2009 Jun).

40. Tendilla-Beltran, H., Antonio Vazquez-Roque, R., Judith Vazquez-Hernandez, A., Garces-Ramirez, L. \& Flores, G. Exploring the Dendritic Spine Pathology in a Schizophrenia-related Neurodevelopmental Animal Model. Neuroscience. PubMed PMID: 30452973. Epub 2018/11/20. eng, 396, 36-45 (2019 Jan 1).

41. Zheng, L. et al. Overexpression of MicroRNA-145 Ameliorates Astrocyte Injury by Targeting Aquaporin 4 in Cerebral Ischemic Stroke. BioMed research international. 2017, 9530951. PubMed PMID: 29057271. Pubmed Central PMCID: PMC5615955. Epub 2017/10/24. eng (2017).

42. Wu, Y. F., Sytwu, H. K. \& Lung, F. W. Human Aquaporin 4 Gene Polymorphisms and Haplotypes Are Associated With Serum S100B Level and Negative Symptoms of Schizophrenia in a Southern Chinese Han Population. Frontiers in psychiatry. 9, 657. PubMed PMID: 30618856. Pubmed Central PMCID: PMC6297372. Epub 2019/01/09. eng (2018).

43. Michelhaugh, S. K. et al. Mining Affymetrix microarray data for long non-coding RNAs: altered expression in the nucleus accumbens of heroin abusers. Journal of neurochemistry. 116(3), 459-66. PubMed PMID: 21128942. Pubmed Central PMCID: PMC3061462. Epub 2010/12/07. eng (2011 Feb).

44. Thoma, P. \& Daum, I. Comorbid substance use disorder in schizophrenia: a selective overview of neurobiological and cognitive underpinnings. Psychiatry and clinical neurosciences. 67(6), 367-83 (2013).

45. Zhou, M., Zhang, X. Y. \& Yu, X. Overexpression of the long non-coding RNA SPRY4-IT1 promotes tumor cell proliferation and invasion by activating EZH2 in hepatocellular carcinoma. Biomedicine \& pharmacotherapy = Biomedecine \& pharmacotherapie. 85, 348-54. PubMed PMID: 27899259. Epub 2016/12/03. eng (2017 Jan).

46. Yang, Y. T. et al. Long non-coding RNA UCA1 contributes to the progression of oral squamous cell carcinoma by regulating the WNT/beta-catenin signaling pathway. Cancer science. 107(11), 1581-9. PubMed PMID: 27560546. Pubmed Central PMCID: PMC5132283. Epub 2016/08/26. eng (2016 Nov).

47. Hoseth, E. Z. et al. Exploring the Wnt signaling pathway in schizophrenia and bipolar disorder. Transl Psychiatry. 8(1), 55. PubMed PMID: 29507296. Pubmed Central PMCID: PMC5838215. Epub 2018/03/07. eng (2018 Mar 6).

48. Park, J \& Belden, W. J. Long non-coding RNAs have age-dependent diurnal expression that coincides with age-related changes in genome-wide facultative heterochromatin. BMC genomics. 19(1), 777. PubMed PMID: 30373515. Pubmed Central PMCID: PMC6206985. Epub 2018/10/31. eng (2018 Oct 29).

49. Harrison, R. N. et al. Gene-expression analysis of clozapine treatment in whole blood of patients with psychosis. Psychiatr Genet. 26(5), 211-7. PubMed PMID: 27315048. Pubmed Central PMCID: 5010277 (2016 Oct)

\section{Acknowledgements}

The current study was supported by a grant from Shahid Beheshti University of Medical Sciences.

\section{Author Contributions}

M.T. and S.G.F. wrote the manuscript and supervised the study. H.F. and I.A. performed the experiment. S.M.N. and V.K.O. analyzed the data. All the authors contribute equally and read the submission.

\section{Additional Information}

Competing Interests: The authors declare no competing interests.

Publisher's note: Springer Nature remains neutral with regard to jurisdictional claims in published maps and institutional affiliations.

(c) (i) Open Access This article is licensed under a Creative Commons Attribution 4.0 International C. License, which permits use, sharing, adaptation, distribution and reproduction in any medium or format, as long as you give appropriate credit to the original author(s) and the source, provide a link to the Creative Commons license, and indicate if changes were made. The images or other third party material in this article are included in the article's Creative Commons license, unless indicated otherwise in a credit line to the material. If material is not included in the article's Creative Commons license and your intended use is not permitted by statutory regulation or exceeds the permitted use, you will need to obtain permission directly from the copyright holder. To view a copy of this license, visit http://creativecommons.org/licenses/by/4.0/.

(C) The Author(s) 2019 